ing they had been sold instead of being unnerved, but on this point I have the very best estimate, viz., that of the owners, who, judging from the prices realised by their cast horses sold at auction, have valued them at $£ \mathrm{r} 8$ each, in all $£ 630$. A more difficult problem was the valuation of the 22 successful cases, but here again I had the same excellent estimate. The owners said that they considered they would be worth, marketably, $£ 40$ apiece, in all $£ 880$, though they considered that this would not represent anything like their value to them as carriage horses, as part of the stock of a going concern, on account of their being seasoned to their work, and being good examples of their class, without which the operation would not have been attempted.

Of the eight failures, one was destroyed, and the other seven, sold at public auction, realised $£ \mathbf{I} 7$. Four of the unsatisfactory number were disposed of in the same way for $£ 54$, one having been destroyed -total, $£$ IO5I. Besides this there was the cost of the keep of the horses after the operation and until they went to work; and taking this at an average of five weeks, calculating the keep at say Ios. per week each horse, we arrive at the sum of $£ 87,10$., which must be deducted from the $f_{105} \mathrm{I}$. This gives $£ 963$, Ios. against $£ 630$, showing a balance of $£ 333$, Ios. in favour of the operation at the end of the first year. Of course the benefit of the operations remains to be taken account of as long as the horses remain in stock, but allowance must be made for their natural deterioration in value as they get older.

I am sorry I cannot say anything very definite about the duration of a horse's life after he has been unnerved. The majority of the successful cases work for two or three years before being cast, and very often their removal then from the stock is in no way connected with the operation. When their courage and action have lasted I have seen a number work five or six years.

In conclusion, I must say the horses operated on were all highclass carriage horses with action-some had grand action-and as this class of animal is extremely difficult to obtain, it behoves us to do all we can to enable them to perform the duties for which they are bought.

\title{
METHODS OF SECURING HORSES FOR OPERATIONS ON THE INGUINAL REGION.
}

By Joseph Donald, F.R.C.V.S., Wigton.

THE apparatus consists simply of an ordinary casting rope or a good cart rope, of sufficient length, and doubled so that one end shall be from two to three yards longer than its fellow of the opposite side. In the first method the longer end administers to the greater part of the tying process, while in the second it is exclusively used.

I. Method for Ordinary Castration. - The ropes are adjusted as in the ordinary way of throwing for castration; the longer end being placed on the left side, the colt is pulled down on his near side, the legs being pulled well up to the body in the usual way. To secure the animal the operator stands at the back of the horse, and, taking the 
uppermost rope, simply twists or half-hitches it twice round the upper fetlock, and then consigns it to an assistant who stands with his knee against the thigh. The left rope is now taken and pulled

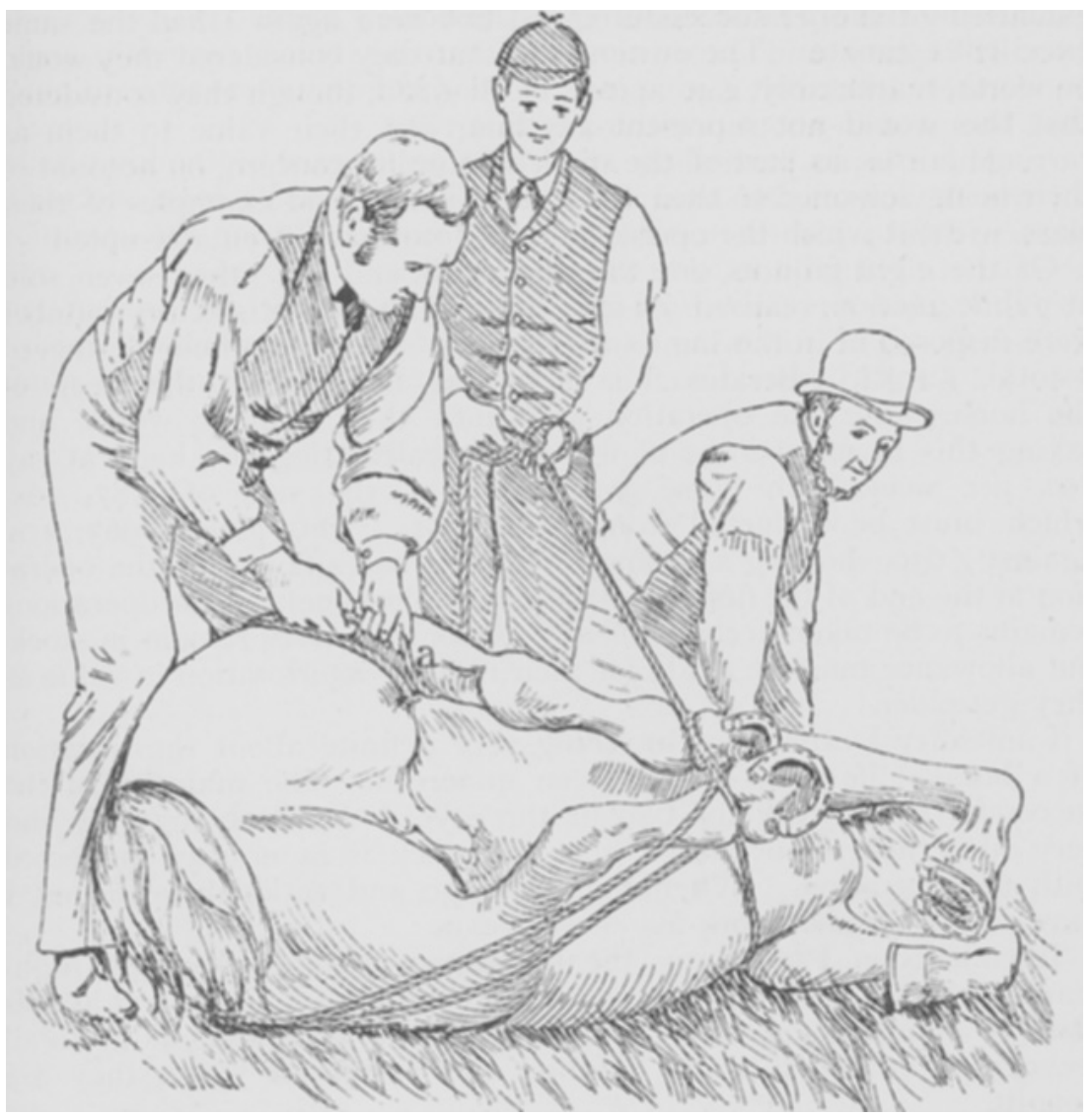

backwards till it comes just over the withers, when it is passed under the upper leg, hitched on the lower fetlock, and then drawn up, and a half hitch put over both feet. The loose end of rope is then passed down and round the quarters a few inches anterior to the root of the tail, then up under thigh, and round the front of the lower hind fetlock. It is now pulled firm, and passed back in the same way, and hitched or wound round the fetlock of the upper foot, then round both feet, and given to an assistant to hold. The operator must now take the upper rope (a) and pass it inside of the thigh, and give to an assistant to hold. This rope is useful if the animal requires to be slightly altered in position, or the thigh abducted, in case the testicle is at all difficult to get into the clam. The fore limbs are not secured; the man at the head sits in the position shown, and the operation is performed with the colt lying on his side.

The above method of securing colts and adult horses has not, so far as I am aware, been previously published. It is the method adopted by a former employer of mine (Mr Carter, Litcham), and I believe it is 
also employed by a number of other Norfolk practitioners. To me this method seems to possess advantages sufficient to render it worth recording:-

I. It is a very safe method, as all the tying and untying is accomplished by the operator standing at the horse's back.

2. It is easy and expeditious, no turning being requisite, and a moderately quiet colt can be cast and tied in from two to three minutes, and liberated in about one-third of that time.

3. There is no struggling and shooting forward of the hind limbs, as the flexion of the hind fetlocks and the quarter rope effectually prevents this; and there is no steadying required during the operation, the patient lying on its side the whole time.

II. Method for Castration and Operations on the Inguinal Region Generally.-The following is a method of securing animals which I devised for Rig castration. It is simple, answers the purpose admir-

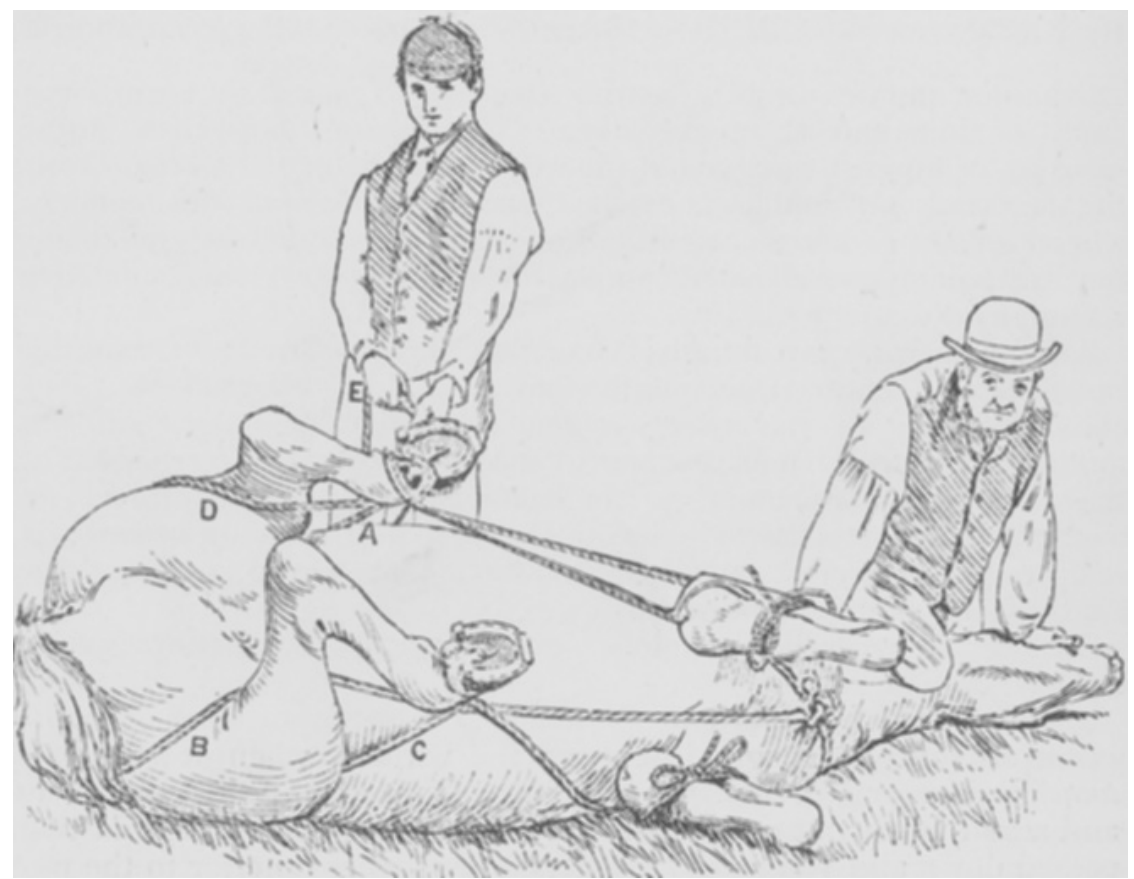

ably, and is equally suitable for any operation on the inguinal region, especially where it is desirable to have the region well exposed and plenty of room:-

Adjust the ropes asforcastration (as described above), putting thelonger rope on the side you wish the animal to fall upon, and throw in the usual way. When the horse is down the operator seizes the under rope, pulls it backwards loosely under the withers, and winds it two or three times round the upper fetlock. He then passes it down in front of the upper stifle $(A)$, backwards and under the quarters, bringing it up inside the opposite thigh $(B)$ and round the front of the lower hind fetlock. The rope is next steadily and firmly pulled until the limbs are well flexed, then wound twice round the lower fetlock, passed down in front of 
stifle $(C)$, over the quarters to the opposite side, and up inside the thigh $(D)$. Now pull firm, wind twice round the upper fetlock, and give the rope (E) to an assistant to hold. The animal's hind feet are thus thoroughly and firmly secured to his own hind quarters. To secure each fore limb take a piece of light cord about a couple of yards long-a piece of good plough line answers well-double it round the fetlock, and pass the loose ends through the loop so formed; then flex the knee, and pass one cord to the inside and the other to the outside under the forearm, and tie on the upper side of the metacarpal bone, as shown in the illustration. The patient can then be placed in any convenient position as required by circumstances.

\section{TUBERCULOSIS IN THE HORSE:}

By J. M‘Fadyean, M.B., B.Sc., Royal Veterinary College, Edinburgh.

IN the first number of this Journal (page $5 \mathrm{I}$ ) I placed on record two cases of tuberculosis in the horse. These cases derived a larger measure of interest than would otherwise have belonged to them from the fact that no similar cases had been described in this country, where, so far as veterinary literature seemed to indicate, the belief that the equine species had a complete immunity from natural infection was generally accepted.

During the past few months I have had the opportunity to examine the principal organs from another case of equine tuberculosis. The clinical history of this case is given at a subsequent part of this number, and what $I$ have to report concerning it must be regarded as the necessary complement to the facts stated by Mr Campbell, in whose practice it occurred. I say necessary complement, because, in such cases, a microscopical examination is required to place the diagnosis beyond doubt or cavil.

The organs specially examined by me were the lymphatic glands, the liver, and the kidneys.

Lymphatic Glands. The bronchial, mesenteric, and hepatic lymphatic glands were greatly enlarged. The largest formed tumours about twice as big as the fist of a man. They had a tolerably firm consistence (firmer than a healthy gland), and on section the largest were found to be extensively caseated towards the centre, and partly calcified. The condition of the glands was thus similar to that of the same parts in the cases previously described in this Journal. It may here be remarked that so great was the alteration of some of the glands in size and appearance, that they might readily have been mistaken for true neoplasms, but their position indicated clearly that they were hyperplastic enlargements of the lymphatic glands.

After hardening in alcohol, sections were cut from the outer less. degenerated part of one of these enlargements. A microscopic examination of such sections stained with picro-carmine or logwood showed what might be described as a diffuse tubercular structure, in which, amid a basis or groundwork of round cells of a lymphoid character, were a great number of giant cells. Sections were next stained by the method of Ehrlich, which revealed the presence of 